\title{
La publicidad televisiva ante el reto de la interactividad ${ }^{1}$
}

Emili Prado | emili.prado@uab.cat

Rosa Franquet | rosa.franquet@uab.cat

Francesc Xavier Ribes | xavier.ribes@uab.cat

María Teresa Soto | mariateresa.soto@uab.cat

David Fernández Quijada I david.fernandez@uab.cat

UNIVERSIDAD AUTÓNOMA DE BARCELONA

Resumen: Este artículo presenta una propuesta de clasificación de las diferentes formas que adopta la publicidad para incorporar la interactividad a sus estrategias comunicativas. La tipología nace de la observación y análisis de los modelos existentes y se presenta como instrumento que facilite la comprensión del fenómeno de la interactividad aplicada a la publicidad, ya sea en sus manifestaciones actuales como en aquellas que, en un futuro, puedan derivarse.

Palabras clave: televisión interactiva, formatos publicitarios, publicidad interactiva.

Abstract: This article presents a proposal for the classification of the different forms used in advertising to include interactivity in communication strategies. This typology is the result of the observation and analysis of existing models and is presented as an instrument that should help develop an understanding of the phenomenon of interactivity when applied to advertising, both in its current forms and in other forms that might be derived from them in the future.

Key words: Interactive television, advertising formats, interactive advertising.

\footnotetext{
${ }^{1}$ Este artículo presenta algunos de los resultados de los proyectos Televisión interactiva en el entorno cross media: tipología de la oferta, los contenidos, los formatos y los servicios emergentes (SEJ 200611245), financiado por el Ministerio de Educación y Ciencia dentro del Plan Nacional I +D+I y Televisió interactiva. Simbiòsi tecnològica i sistemes d'interacció amb la televisió, financiado por el Consell de l'Audiovisual de Catalunya.
} 
La publicidad, como forma de comunicación, siempre se ha mostrado ágil para adaptarse a los cambios sociales, a las tendencias y a las modas, resultando ser, en incontables ocasiones, parte del sistema difusor e impulsor que ha favorecido la implantación de esos cambios.

También ha liderado innovaciones creativas en la forma de contar y comunicar. Pero lo más destacado es que, en ese continuo estado de adaptación, la publicidad se ha preocupado constantemente por encontrar nuevas maneras de relacionarse con el medio de comunicación que la acoge.

La televisión digital terrestre (TDT) ofrece nuevas posibilidades de interactividad al poder acompañar los contenidos audiovisuales con el $20 \%$ de la banda de datos de cada canal múltiple de TDT que en el Plan Técnico Nacional de la Televisión Digital Terrestre (Real Decreto 944/2005, de 29 de julio $^{2}$ ) se reserva para servicios adicionales, entre los que cabe incluir los interactivos. Este hecho abre la puerta a nuevas formas de comunicación que ofrecen a los creativos publicitarios herramientas comunicativas basadas en la interactividad que no pueden ser obviadas. Otras plataformas para la televisión digital (cable, satélite, ADSL, wireless o la telefonía de tercera generación) disponen igualmente de otras características técnicas que posibilitan la interacción.

Lo que técnicamente constituye una posibilidad se convertirá, por obligaciones de mercado, en una necesidad, ya que "en un marco televisivo dominado por el aumento de competencia y la fragmentación de las audiencias, la publicidad busca nuevas maneras de sustituir cualitativamente la pérdida cuantitativa de audiencia que presentan sus formatos tradicionales" (Prado y Fernández Quijada, 2007).

\section{Estructura}

El presente artículo presenta una reflexión sobre las transformaciones que afectan a la publicidad en el incipiente campo de la televisión interactiva (TVi). Este nuevo entorno es el que se delimita en la primera parte del análisis a partir de los tipos de interactividad existentes y de la caracterización de la oferta de servicios interactivos. A continuación, se señalan las primeras experiencias publicitarias españolas en TVi y se hace una propuesta tipológica de formatos a partir, igualmente, de la oferta publicitaria que se ha desarrollado a través de la TVi. Finalmente, se exploran los primeros pasos que la televisión interactiva, y con ella la publicidad, está dando en Internet y en los dispositivos móviles.

\footnotetext{
${ }^{2}$ Boletín Oficial del Estado, № 181, 30 de julio de 2005.
} 


\section{Análisis}

En entornos de TVi podemos encontrar actualmente tanto mensajes publicitarios convencionales como interactivos.

Entendemos por formatos convencionales aquellos que utilizan exclusivamente el lenguaje y las posibilidades tecnológicas propias de la televisión de flujo tradicionalmente entendida. La frontera entre "convencional" y "no convencional", en nuestro caso, se establece a partir de la posibilidad de interacción. En otras palabras, proponemos como formatos convencionales los mensajes publicitarios audiovisuales diseñados para un consumo lineal, con inicio y final predeterminados por el emisor, y en los que el receptor no tiene capacidad de alterar la linealidad mencionada ni puede ejercer ningún otro tipo de interacción sobre el mensaje, más allá de la decisión consciente de mirarlos o no. Los mensajes publicitarios convencionales no aprovechan las ventajas de la interactividad, aunque la naturaleza de la publicidad sea precisamente ésa: una respuesta del público en forma de compra del producto o servicio publicitado.

En líneas generales, podemos entender por publicidad interactiva todo el conjunto de aplicaciones concebidas en cualquier formato publicitario que permitan que el usuario ejerza una interacción situacional.

La interactividad situacional se da siempre que sea posible una acción mutua entre los dos polos del proceso de comunicación, en este caso entre la aplicación publicitaria y el usuario. Para que sea posible esa acción mutua debe estar prevista en la arquitectura de la aplicación. Para ejercerla puede requerirse o no una vía de retorno. De tal modo podemos diferenciar entre interactividad situacional e interactividad tecnológica. La primera se da siempre que se produce una acción mutua entre los polos y la segunda siempre que esa acción mutua requiera la existencia de una línea de retorno (Gráfico I).

\subsection{Caracterización de la publicidad interactiva}

Como el resto de los servicios y aplicaciones interactivas que se ofrecen en la TVi, los mensajes publicitarios pueden clasificarse en alguna de las tres categorías establecidas por Prado et al. (2006: 13-14): Servicios Interactivos Autónomos (SIA), Servicios Interactivos Asociados a Programas (SIAP) o Programas Audiovisuales Interactivos (PAI).

Así, un SI A publicitario es una aplicación accesible con autonomía del flujo de programas, disponible en todo momento para el usuario que la desea contactar, 24/7, todo el día, toda la semana. Un SIAP publicitario es aquél que ha sido creado para ser accesible en sincronía con un determinado programa, espacio o spot y se vincula directamente con él. Finalmente, un PAI publicitario es un programa completo, con contenidos de carácter comercial concebido para permitir la interacción del usuario. 
Cabe señalar que, aunque no existe ninguna norma jurídica específica para la publicidad interactiva, la Comunicación interpretativa de la Comisión relativa a algunos aspectos de las disposiciones de la Directiva «Televisión sin fronteras» sobre la publicidad televisiva (C 102/02) afirma, de una forma genérica, que la publicidad interactiva "permite al telespectador dar información directamente al organismo de radiodifusión gracias a un sistema de respuesta o actuar de manera interactiva en un entorno al que se expone voluntariamente". Esta definición encaja con la clasificación propuesta en el presente artículo y abarca tanto la interactividad tecnológica (hace referencia a "un sistema de respuesta") como a la situacional (al mencionar que permite "actuar de manera interactiva").

De todas formas, parece evidente que los miembros de la Comisión, al definir publicidad interactiva, excluyen intencionadamente los entornos de televisión a través de Internet y piensan únicamente en plataformas de televisión digital al uso, ya sean hertzianas, satelitales o de cable. Así que la popularización de los sistemas de vídeo webcasting en Internet o la reciente irrupción de la IPTV, obliga a retomar la definición de publicidad interactiva y rehacerla con el fin de adecuarla al entorno. De lo contrario, como suele ocurrir, quedará una "tierra de nadie" donde la ambigüedad de la legislación provocará diferentes conflictos de intereses entre anunciantes y consumidores televisivos, en terrenos como la saturación publicitaria, la exposición a intensidades sonoras sobresaturadas e irrupciones extemporáneas de la narración televisiva. Estas malas prácticas actuarían en la práctica como un freno al desarrollo de la publicidad interactiva.

Puesto que nos encontramos en un primer estadio de desarrollo e implementación de mensajes publicitarios interactivos en entornos televisivos, para que los espectadores participen de la interacción propuesta resulta imprescindible familiarizarlos con la experiencia de la interacción televisiva. No basta simplemente con introducir la tecnología necesaria en sus hogares, sino que "el éxito de este medio depende de la habilidad y la predisposición de la audiencia televisiva a cambiar sus hábitos de visionado e involucrarse más activamente" (Levy y Nebenzahl, 2006: 310). Muchos de los mensajes publicitarios observados promueven la participación del usuario ofreciéndole algún tipo de incentivo por el simple hecho de acceder a la sección interactiva del anuncio.

El reclamo, que puede prometer un premio directo o la inclusión en un sorteo, solía presentarse originalmente como un banner superpuesto al mensaje audiovisual convencional, normalmente con forma rectangular y situado en posición horizontal, centrado en la parte inferior de la pantalla. No obstante, cada vez más, el reclamo evoluciona hacia formas más llamativas y de mayor tamaño, ocupando zonas importantes de la pantalla. Así, la intrusión que supone esta sobreimpresión obliga al usuario a interactuar, ya sea para acceder al mensaje interactivo o para ocultar el reclamo y continuar con la exposición al mensaje convencional. Pero las formas de publicidad intrusiva, tan denostadas en Internet (y que las agencias suelen rechazar al plantear campañas vía web), se utilizan sistemáticamente en televisión. En lugar de imaginar maneras más sugerentes de inducir a 
la exposición voluntaria al mensaje persuasivo, son muchas las campañas que fuerzan al espectador televisivo, irrumpiendo sin permiso y bruscamente en el flujo comunicativo establecido, provocando de este modo un clima de rechazo a los mensajes publicitarios en general.

En cuanto a su estructura, todo mensaje publicitario interactivo se compone de dos partes: unos contenidos audiovisuales convencionales, que pueden haberse producido expresamente para la campaña interactiva o ser parte del mismo material emitido en la campaña de televisión lineal; y la aplicación interactiva, que permitirá obtener los contenidos o servicios añadidos anunciados en el mensaje publicitario interactivo. Estos servicios consisten, generalmente, en el acceso a información audiovisual adicional, la solicitud de un catálogo del anunciante, la participación en sorteos y juegos, la realización de un donativo o, incluso, la formalización de la compra o la contratación del producto o servicio publicitado.

\subsection{Presencia de la publicidad interactiva en la oferta televisiva}

Aunque puede parecer que los programas interactivos en general y la publicidad interactiva en particular es algo muy reciente, las primeras experiencias de mensajes publicitarios interactivos en las televisiones españolas se remontan a 1998. Entonces, la empresa TVC Multimèdia, vinculada al ente público Corporació Catalana de Radio i Televisió (CCRTV), desarrolló la primera aplicación interactiva para la campaña publicitaria del Renault Clio, que se emitió en Canal Satélite Digital el 29 de junio de 1998. Ésta y otras experiencias de publicidad interactiva pioneras en el estado español se muestran en el Cuadro I. Todas ellas se caracterizan por utilizar como plataforma de emisión el satélite.

La publicidad interactiva puede aparecer en cualquier tipo de programa o servicio de TVi, adecuándose a sus propiedades.

Así, en los SIA, suele haber mensajes de esponsorización (u otro tipo de inserciones publicitarias) en los que domina el banner o los botones activos para desencadenar la interacción.

Los SIA en los que se ubica más publicidad son tres: las guías electrónicas de programación (Electronic Program Guides, -EPG-), los llamados walled gardens y las agrupaciones publicitarias. En las EPG predominan los banners y los botones. En un walled garden (espacio restringido sólo a subscriptores o abonados), además de banners y botones, se pueden encontrar mensajes splash-screen, composiciones intrusivas y no solicitadas que ocupan toda la pantalla y que aparecen al pasar de una página a otra; también suele haber juegos, esponsorizados por algún anunciante. Finalmente, en la agrupación temática de anuncios interactivos, se presenta un "nuevo formato" de programa que consiste en ofrecer al usuario, de forma continua, todos los mensajes publicitarios sobre una gama de productos para que pueda informarse, comparar y, si está interesado, comprar. 
Por lo que se refiere a los SIAP, también predominan los banners y los botones activos. Normalmente los mensajes publicitarios asociados a programas corresponden a un anunciante que esponsoriza el programa al que se vincula el servicio interactivo.

En los PAI se presentan las formas tradicionales de inserción publicitaria, la esponsorización, la sobreimpresión y los spots en las pausas publicitarias. Estos anuncios están diseñados para alcanzar dos niveles de impacto: el tradicional de la exposición lineal, es decir, la exposición al mensaje por parte del receptor; y el interactivo, reservado a los usuarios que decidan interactuar. Es evidente que el grado de implicación con el mensaje por parte del usuario que decide interactuar es muy elevado puesto que accede a él de forma voluntaria y tras haber despertado en él cierto interés, ofreciendo deliberadamente su atención.

Teóricamente, publicidad interactiva y telecomercio son conceptos claramente delimitados. En líneas generales podemos decir que la publicidad interactiva hace referencia al desarrollo de procesos comunicativos y el telecomercio se centra en el establecimiento de relaciones de compraventa. En el entorno de la TVi, la frontera entre publicidad interactiva y telecomercio parece diluirse, dado que una misma pieza de publicidad interactiva, y por tanto con intenciones comunicativas, puede incluir otra aplicación que inicie un proceso de telecomercio. Esto no debe llevar a confusión: mientras que la formalización de cualquier proceso de compra entra en el campo de las transacciones y debe estar sujeta a la regulación del comercio electrónico, incluso si se efectúa a través del medio televisivo, el resto de la publicidad debe someterse al control de la regulación de contenidos y a las normas específicas que atañen a la publicidad. Una separación que parece cuestionarse ante las formas cada vez más integradas que adquieren ambas.

\subsection{Tipología de formatos}

Si los formatos publicitarios están en continuo proceso de evolución debido al dinamismo de la propia industria televisiva, más aún cabe señalar la juventud de la publicidad interactiva y, en consecuencia, de sus formatos. Se trata, pues, de un campo en fase todavía inicial en el que ya empiezan a aparecer propuestas tipológicas. Entre las más recientes podemos destacar las de Carrillo Durán (2005) y Cauberghe y De Pelsmacker (2006).

La primera de éstas distingue, a partir de la televisión digital por satélite, hasta cinco formatos comerciales, orientados a la transacción electrónica, y dos más puramente publicitarios. Cauberghe y De Pelsmacker, por su parte, idean su tipología de formatos a partir del nivel de integración de la publicidad con el flujo televisivo, estableciendo hasta once categorías y cuatro subcategorías.

La aproximación que se propone en este artículo, en cambio, podría calificarse de modular, ya que parte de los formatos publicitarios ya establecidos (spot, sobreimpresión, product placement, etc.) para definir cuatro grandes categorías de formatos interactivos que hacen 
referencia únicamente a la parte interactiva de estas aplicaciones. Es decir, esta tipología se establece en dos niveles: por un lado, una base en la que se halla el formato publicitario convencional; si a éste se le ha decidido aplicar una capa interactiva, ésta se adscribirá a uno de los cuatro formatos definidos atendiendo a su morfología y al uso que hace de los recursos audiovisuales.

La ventaja principal de una clasificación que parta de esta división en capas reside en la posibilidad de combinar formatos interactivos tanto con mensajes publicitarios convencionales como no convencionales. Ello puede ser muy útil a la hora de planificar campañas que combinen linealidad e interactividad y puede ayudar a introducir paulatinamente estos nuevos formatos interactivos.

Así, a partir de los ejemplos desarrollados actualmente por la industria, en esta clasificación se diferencian cuatro grandes grupos de mensajes publicitarios interactivos: los llamados Dedicated Advertiser Location (DAL), los Microsites, los TVsites y los Impulse Response.

\subsubsection{DAL}

Los Dedicated Advertiser Location o DAL son espacios exclusivamente publicitarios, diseñados para conducir al interactor a la obtención de información relacionada con el producto o servicio ofertado. El aspecto y uso de los DAL es muy similar al de los menús de un disco DVD: el interactor, con el mando a distancia, puede moverse por un menú y seleccionar alguna de las posibilidades mostradas para acceder a los diferentes nodos de información disponibles. Se observa, en la oferta disponible, que los anunciantes utilizan este tipo de mensajes publicitarios como una herramienta de relación entre la marca y sus potenciales consumidores más que como un entorno para obtener respuestas, datos o información de los interactores. Se puede interpretar que la interacción en los DAL proporciona el grado de inmersión suficiente como para favorecer esa relación entre la empresa y el cliente potencial que, al interactuar, muestra su interés hacia el producto o servicio mostrado, y manifiesta una predisposición positiva hacia la empresa anunciadora o hacia sus productos o servicios.

Además de texto, imágenes y audio, los DAL destinan un cuarto de pantalla para mostrar material videográfico y se forman con dos o más pantallas a través de las que se puede navegar, ofreciendo libertad al interactor con respecto al orden en que decide acceder a los diferentes nodos de información.

Una variante de este formato es el denominado mini-DAL. En este formato, el número de pantallas se limita a una o, a lo sumo, dos y no se utiliza vídeo. Cuando el mini-DAL se reduce a una única pantalla, la interactividad queda restringida a determinar el inicio y el final del consumo, es decir, a establecer la duración de la exposición al mensaje. Cuando las pantallas que componen el mini-DAL son dos, además de poder determinar la duración, se ofrece una interactividad selectiva de navegación limitada a intercambiar ambas pantallas. 


\subsubsection{Microsites}

Los microsites, por su parte, no cuentan con información videográfica. El espectador, como en el caso de los DAL, debe renunciar al flujo televisivo para entrar y moverse por los contenidos ofrecidos mediante este formato publicitario. De hecho, son muy similares a los primeros sitios web, tanto visualmente como en la forma de navegar por ellos, lo cual facilita su uso por parte de los interactores. Suelen utilizarse para posicionar la imagen de marca de la empresa anunciante, en campañas promocionales o para proporcionar una amplia información de ofertas y servicios concretos. Una ventaja de los microsites es que su coste de producción es relativamente barato.

\subsubsection{TVsites}

Los denominados TVsites podrían entrar en la categoría de "pantalla dividida", tal como la describe la mencionada Comunicación interpretativa de la Comisión sobre la publicidad televisiva con un par de matices. La publicidad de pantalla dividida aparece sin que el usuario la demande y ocupa sólo una cuarta parte del espacio del televisor. En cambio, la información de los TVsites aparece sólo si el usuario lo permite y es el flujo televisivo (y no la comunicación publicitaria) la que pasa a ocupar el $25 \%$ de la pantalla. Así, la atención del espectador, como la pantalla, queda dividida y mientras las imágenes y el sonido de la programación televisiva se reduce a una ventana, el resto se destina al espacio informacional publicitario y a la aplicación interactiva que permite obtener el servicio ofrecido por el anunciante.

Este formato publicitario es sencillo y económico de producir, puesto que utiliza solamente texto e imágenes fijas. Por ello resulta una opción muy frecuente entre los publicitarios. Además, se ha mostrado como una excelente herramienta para conocer aspectos concretos de los usuarios, obteniendo un elevadísimo índice de respuestas, seguramente debido a la facilidad de uso, al acceso a los contenidos de la comunicación publicitaria sin renunciar al flujo programático y (sobre todo) a la ya mencionada oferta de incentivos en forma de premios o sorteos.

Conviene destacar que las agencias publicitarias no suelen distinguir entre Microsite y TVsite y utilizan ambos términos como sinónimos. No obstante, la coexistencia del flujo programático con los contenidos publicitarios del TVsite y la atención exclusiva sobre el mensaje persuasivo que permite el Microsite son características definitorias y suficientemente relevantes como para poder establecer estas dos categorías diferenciadas.

\subsubsection{Impulse Response}

El último de los cuatro formatos interactivos es el denominado Impulse Response. Es el formato más sencillo y económico para producir mensajes publicitarios interactivos. Consiste 
en una aplicación que aparece superpuesta sobre el flujo programático, en forma de banner rectangular o, cada vez más, con un reclamo de diseño más complejo. Igual que los TVsites, no exigen desconectar la atención de los contenidos televisivos y proporcionan un elevado índice de respuesta por parte de los usuarios. Se utilizan para ofrecer muestras, catálogos o información adicional que se harán llegar al telespectador a través del correo convencional. A cambio, el anunciante suele plantear al usuario dos o tres preguntas sobre sus preferencias o hábitos de consumo, consiguiendo valiosa información, directamente de potenciales clientes interesados, en mayor o menor medida, por sus productos o servicios. Este intercambio de información persigue "facilitar relaciones más fuertes y eficientes entre el anunciante y el consumidor" (Schumann, Artis y Rivera, 2006: 20).

\subsection{Cambios en el consumo televisivo y nuevos soportes publicitarios}

Dos tendencias parecen marcar el futuro inmediato del acceso a los contenidos audiovisuales y empiezan a definir nuevos hábitos de consumo televisivo: la ubicuidad del acceso a la red y la distribución de material videográfico mediante las redes de telefonía e Internet.

Hasta no hace mucho las conexiones a Internet dependían, indefectiblemente, de una roseta telefónica anclada en la pared. El usuario pagaba a su proveedor de acceso a Internet por conectarse a la Red a través de una línea telefónica, vinculada a un inmueble en concreto: el modelo de contratación seguía las pautas de la prestación de otros servicios que dependen de la existencia de una red física a través de la cual canalizar el flujo contratado, como el suministro de agua o la distribución de luz eléctrica. Así, los datos que circulaban por Internet se trataban como un flujo que dependía de un canal físico concreto, vinculado a una línea de teléfono determinada. Por tanto, si el usuario abandonaba temporalmente el emplazamiento de su conexión (saliendo de viaje, por ejemplo) a pesar de estar pagando por el servicio de acceso a Internet, no podía utilizarlo, ya que sólo lo podía hacer desde la línea telefónica para la cual lo había contratado (su hogar, su despacho...).

No obstante, el carácter virtual de los datos y la posibilidad de establecer canales inalámbricos para estos datos ha permitido que el acceso pueda establecerse a través de conexiones y redes desvinculadas de un espacio físico, que cada vez son más potentes, más extensas y de mayor cobertura. Igualmente, han aparecido en el mercado dispositivos que permiten la conexión a través de líneas de telefonía móvil, garantizando un elevado grado de movilidad y de ubicuidad de acceso.

Igualmente, los dispositivos móviles (ya no podemos llamarlos simplemente teléfonos móviles), además de aumentar el tamaño de pantallas y de memorias, mejoran en cuanto a prestaciones de acceso a la red. Son susceptibles de funcionar como una ventana de recepción de material videográfico. De hecho, las primeras experiencias de creación de contenidos específicos para dispositivos móviles, como los mobisodes de "24: Conspiracy" o de "Head \& Body", han servido para establecer un modelo de negocio creciente. La 
productora Globo Media, con la serie de ficción "Supervillanos", fue pionera en la producción de ficciones para dispositivos móviles destinada al mercado español.

Es interesante resaltar que el usuario de telefonía móvil en concreto está habituado a una "cultura del pago" frente a la cultura de la "gratuidad del usuario" de Internet. De hecho, el mercado de la personalización del móvil (tonos, fondos de pantalla, "yavoys"...) es un mercado en creciente expansión que mueve cifras millonarias. Resultan, por tanto, un segmento de la población muy atractivo, comercialmente hablando. Además, la concreción de los estándares para visualizar la emisión televisiva en directo o en diferido desde el móvil ofrece nuevas oportunidades a los creadores publicitarios. En Japón, dónde este proceso se encuentra muy avanzado y los umbrales de usos de móviles muy extendidos, diferentes compañías ofrecen servicios de distribución de programas televisivos con asociaciones de interacciones en determinados momentos de la emisión. La posibilidad de la tecnología móvil para facilitar las transacciones comerciales abre todo un sin fin de posibilidades para sector publicitario que dispone de un soporte idóneo para planificar campañas específicas capaces de llegar a individuos cautivos. Por otra parte, desde hace años los emisores han establecido una nueva conexión con la audiencia a través de los envíos y sistemas de alerta SMS o MMS. Igualmente, una parte significativa de la audiencia está acostumbra a las consultas que se responden con el móvil y que se saldan con un coste.

El otro aspecto destacable es la conquista de Internet por parte del vídeo. Los sistemas de compresión, el aumento del ancho de banda y el diseño de tecnologías streaming permiten distribuir contenidos audiovisuales con una calidad visual y sonora cercana al estándar del DVD.

No debemos olvidar las descargas de material videográfico, realizadas a través de las redes de intercambio P2P, que permiten al usuario, tras comprar o intercambiar una película o el último capítulo de su serie favorita, verla en la pantalla de su ordenador o, incluso, en el televisor del salón de su hogar, sin depender de los horario en que el programador del canal haya decido pasar la serie, sin interrupciones publicitarias y sin someterse a los cambios imprevistos causados por las estrategias de contraprogramación.

Así, los productores de contenidos audiovisuales utilizan dos nuevos canales de distribución que, por ende, se han convertido en soportes publicitarios: Internet y las redes de telefonía móvil. Ambos canales, por sus características técnicas, posibilitan, y casi exigen, que el diseño de contenidos publicitarios sea interactivo. A simple vista, son dos las razones que llevan a potenciar la interactividad en estos soportes publicitarios: la juventud de sus usuarios, acostumbrados a las nuevas tecnologías y a no ser sujetos pacientes en el proceso comunicativo; y las posibilidades tecnológicas que, en el caso de Internet (a la que también se puede acceder a través de dispositivos móviles), no están restringidas por los encorsetamientos de estándares de los middlewares de la televisión interactiva. 
A pesar de que parece tan evidente, encontramos experiencias que insisten en incluir formas intrusivas de publicidad que no hacen uso alguno de la interacción. Así, se utilizan formas publicitarias emparentadas con la televisión convencional: antes de mostrar el contenido solicitado por el usuario, se le obliga a ver un mensaje publicitario, a modo de spot, sobre el cual no tiene ningún control (no ha decido los contenidos, no puede saltarlo, no puede avanzar rápido...). Es cierto que, como telespectadores, estamos acostumbrados a esta práctica. Pero también es cierto que la aparición de contenidos no deseados en Internet aumenta los tiempos de espera y consume parte del ancho de banda que, además, está siendo pagado por el internauta. Estas formas publicitarias, hasta la llegada del vídeo a la Red, no eran muy habituales en Internet y todavía pueden producir cierto rechazo en el usuario. A pesar de esto, la libertad de elección del usuario sobre el enorme conjunto de contenidos disponibles concede al anunciante un conocimiento sobre los intereses y preferencias del internauta que puede aprovechar como una ventaja puesto que puede relacionar unos mensajes en concreto con ciertos contenidos videográficos, acordes con el perfil de los usuarios que quieran ver esos contenidos. De esta forma, el mensaje publicitario se dirigirá a un target adecuado, muy definido, con características comunes y conocidas que, incluso, puede llegar a captar su atención a pesar de no haber sido solicitado.

\subsubsection{Experiencias en la red: el caso de $A B C$}

No es objeto de este texto la descripción de los formatos publicitarios no interactivos o aquellos que, aun siéndolo, son formatos estándar, utilizados en páginas web sin ningún tipo de vinculación con la distribución de contenidos televisivos como el banner, las ventanas emergentes, los interstitials, las layers o los adpointers aunque, evidentemente, también pueden utilizarse en los sitios de Internet que se acercan a la comunicación televisiva.

Es en este sentido que algunos sitios en Internet desarrollan formas publicitarias que evolucionan a partir de la mezcla de aspectos de la publicidad televisiva convencional con los de la publicidad de la televisión interactiva y los de la propia Internet. Resulta reseñable como caso de estudio la propuesta de la cadena estadounidense $A B C$, que ofrece gratuitamente en Internet los capítulos de sus series de éxito.

La experiencia de esta cadena permite la visualización a través de Internet de los capítulos emitidos por la cadena. El acceso a este material se realiza en streaming, lo que resulta beneficioso tanto para el espectador como para la cadena: el espectador no está obligado a descargar completamente el material y, por tanto, puede empezar a ver el capítulo tan pronto lo selecciona, sin esperas; y la cadena sabe que, al menos, no ha facilitado la descarga de sus producciones al equipo de los espectadores y, por tanto, no ha favorecido la distribución de copias sin su autorización, manteniendo el control sobre el número de veces que se ha visto un capítulo, si se ha visto completamente, etc...

Los diferentes episodios están disponibles en la Red a partir del día siguiente en que se han pasado por la televisión convencional. Para preservar los derechos de distribución, la web de 
acceso a este material está restringida a ordenadores ubicados en Estados Unidos. Así, posteriormente, pueden optar por la venta de estas series a otras televisiones sin que, en principio, hayan sido vistas por espectadores ubicados en otras áreas geográficas.

Esta nueva forma de distribución televisiva se está aprovechando también como soporte publicitario. Cada uno de los capítulos disponibles está esponsorizado por un anunciante, lo cual se comunica al espectador al inicio del episodio con un mensaje de 10 segundos. Además, durante la visualización del capítulo seleccionado, de entre 40 y 50 minutos de duración, se dan tres pausas publicitarias de, como máximo, 30 segundos cada una. El espectador sabe exactamente cuándo se interrumpirá el episodio y aparecerá un anuncio gracias a que la barra de control de la línea de tiempo del vídeo (la que, con un cursor, indica en qué momento de la secuencia temporal se encuentra), tiene tres zonas marcadas con un color más intenso.

Aunque el espectador tiene el control sobre el vídeo (puede avanzar, retroceder, pausar...), éste se ve limitado por dos posibles causas: durante, como máximo, 30 segundos en las pausas publicitarias; al intentar acceder a una parte del capítulo sin haber visto el anuncio que precede a ese fragmento.

Los mensajes publicitarios tienen forma de DAL. Así, al entrar en la zona de anuncio, desaparece la interfaz de visualización y aparece un espacio íntegramente dedicado al producto o servicio anunciado. Un contador en la parte inferior derecha informa de los segundos que quedan antes de que el usuario pueda volver al flujo videográfico de la ficción que estaba viendo. Durante estos 30 segundos, el usuario puede navegar por el espacio publicitario, ver nuevos vídeos, acceder a la web del anunciante, etc. Pasados esos 30 segundos, el espectador puede decidir continuar expuesto al mensaje persuasivo o regresar al capítulo.

Se produce así una mezcla entre publicidad interactiva, publicidad televisiva convencional y publicidad en la Red que adapta diferentes recursos de forma creativa para integrar la publicidad con las características del soporte.

En primer lugar, podemos destacar el ofrecimiento mismo de los contenidos televisivos a través de Internet. La cadena, conocedora de la existencia de las redes P2P y de la distribución que en ella se hace de sus materiales, lejos de intentar frenar esa práctica (lo cual, por otra parte, resulta imposible), opta por convertirse en distribuidora oficial de su propio material, de forma gratuita, garantizando la calidad y con tecnología streaming, situándose para sus usuarios en la posición de banquero simbólico que le guía en un mundo digital de hiperabundancia de contenidos (Fernández Quijada, 2007). Así, puede haber usuarios que, en lugar de descargar los contenidos de una fuente desconocida, prefiera verlos a través del sitio de la $A B C$, gratis, de forma inmediata y con la garantía de la cadena de ser realmente el material correcto y de una calidad aceptable. 
El grado de intrusión de la publicidad sobre los contenidos se mitiga con el conocimiento previo del momento en que aparecerá el mensaje publicitario. Igualmente, la brevedad de la interrupción ( 30 segundos obligatorios a lo sumo) y su número (sólo tres veces en un episodio de entre 40 a 50 minutos) minimizan lo que, para el usuario, podría ser una molestia. Y más si lo compara con el pase televisivo, donde tanto el número de pausas como su duración son mucho mayores.

Pero lo que puede resultar más importante es que el espectador, una vez expuesto al mensaje publicitario, es libre de permanecer en él, consumirlo voluntariamente, con la atención plenamente dedicada y mostrando un alto grado de interés por el producto o servicio publicitado. Aunque todavía no se ha hecho público ningún estudio, parece evidente que ese espectador televisivo, convertido en receptor activo de un mensaje publicitario por el que manifiesta un especial interés y al que regala su atención, resultará ser un cliente potencial de mayor valor para el anunciante que el espectador pasivo del televisor que, probablemente, no se encuentra delante del aparato durante la batería de spots o aprovecha la pausa publicitaria para hacer zapping.

\section{Conclusiones}

La clasificación tipológica presentada tiene la intención de facilitar la comprensión del fenómeno con un alcance amplio y lo suficientemente flexible para que en ella encajen tanto los formatos publicitarios vigentes como aquellos otros que puedan ir surgiendo. Se concibe, por tanto, como un punto de partida en el estudio de las formas adoptadas por la publicidad en la TVi más que como una forma exhaustiva y cerrada de etiquetar los mensajes publicitarios interactivos.

Cabe señalar que la hibridación televisión/Internet es una tendencia evidente, observada tanto en la producción y distribución como en el consumo de mensajes audiovisuales. La ofensiva comercial de distintos actores presentes en el mercado con sus ofertas de triple play acelera esta tendencia. Así pues, las posibilidades de tener un paquete disponible en el hogar de un único proveedor y con servicios de telefonía, televisión y acceso de banda ancha a Internet facilitan los nuevos consumos audiovisuales procedentes de fuentes diversas. En este proceso, las posibilidades interactivas de un medio complementan las capacidades audiovisuales del otro y viceversa.

El caso de la $A B C$ es una muestra de esta interconexión de la televisión, medio de masas y de penetración universal con Internet, medio interactivo por naturaleza, antojándose un modelo en la producción y distribución televisiva que promete un vasto campo de implementación de publicidad interactiva.

Igualmente, la exhibición del material audiovisual proveniente de la Red en el televisor principal del salón, ya sea mediante tecnologías específicamente diseñadas al efecto (como los media center), o a través de opciones de otros dispositivos electrónicos (como la ofrecida 
por la consola Wii de Nintendo) favorece el consumo de Internet, reubicándolo en un lugar prominente del hogar.

Esto, unido al crecimiento exponencial de usuarios de Internet y de la telefonía móvil apunta a un aumento del consumo de contenidos audiovisuales distribuidos a través de las redes. Por tanto, ciertas campañas deberán definirse adecuando sus estrategias de comunicación al denominado entorno cross media.

Asimismo, el uso de estos medios, al menos de momento, caracteriza a ciertos colectivos socio-económicos que quedan convertidos, así, en targets específicos y bien definidos para los propósitos publicitarios.

Y es muy posible que éstos, cada vez más, se acompañen de publicidad, puesto que la audiencia aumenta y se consolida. $\mathrm{Y}$ debido al carácter innovador y adaptable de la publicidad y a su intencionalidad persuasiva recurra a la interactividad como una opción de alto valor comunicativo.

Finalmente el carácter selectivo y esencialmente no intrusivo que puede tener la publicidad interactiva, puede contribuir a generar unas prácticas publicitarias más eficientes y a mitigar las altas tasas de rechazo generado por el carácter intrusivo de la publicidad convencional en la televisión y el alto grado de saturación. 


\section{REFERENCI AS BI BLI OGRÁFICAS}

CARRILlo DURÁN, Mạ Victoria (2005): “La televisión digital. La metamorfosis publicitaria en la televisión digital", en Telos, no 62, pp. 31-41.

Cauberghe, Verolien, y De Pelsmacker, Patrick (2006): “Opportunities and Thresholds for Advertising on Interactive Digital TV: A View from Advertising Professionals", en Journal of Interactive Advertising, vol. 7, no 1, pp. 25-40, en http://jiad.org/vol7/nol/cauberghe/index.htm (consultado: 27/08/2007).

COMISIÓN EUROPEA (2004): Comunicación interpretativa de la Comisión relativa a algunos aspectos de las disposiciones de la Directiva «Televisión sin fronteras» sobre la publicidad televisiva, DOCE C 102/2. Brussels, 28 de abril, en http://europa.eu/scadplus/leg/es/lvb/l24102.htm (consultado: 20/ 07/2007).

FERNÁNDEZ QuIJADA, David (2007): “Industrias culturales en el entorno digital: una reformulación desde la praxis comunicativa", en Zer, no 22, p. 119-140.

LEVY, Shalom, y NeBENZAHL, Israel D. (2006): "Programme involvement and television behaviour in interactive television", en International Journal of Advertising, vol. 25, no 3, pp. 309-332.

Prado, Emili, y Fernández QuIJAdA, David (2007): “Servicios de televisión interactiva en España: una historia de claroscuros", en Javier MARZAL y Andreu CASERO (eds.): El desarrollo de la televisión digital en España. Oleiros, Netbiblo, en prensa.

Prado, Emili et al. (2006): Televisió interactiva. Simbiosi tecnològica i sistemes d'interacció amb la televisió. Barcelona, Consell de l'Audiovisual de Catalunya, en http://www.cac.cat/pfw_files/cma/recerca/quaderns_cac/ tvi.pdf (consultado: 20/07/2007).

Schumann, David W., Artis, Andy, y RiverA, Rachel (2001): "The Future of Interactive Advertising Viewed Through an IMC Lens", en Journal of Interactive Advertising, vol. 1, no 2, pp. 16-32, en http://iiad.org/voll/no2/ schumann/index.htm (consultado: 02/07/2007).

[Recibido: 03-10-2007. Aceptado: 05-11-2007] 


\section{ANEXO: GRÁFI COS Y TABLAS}

\section{I nteractividad situacional}

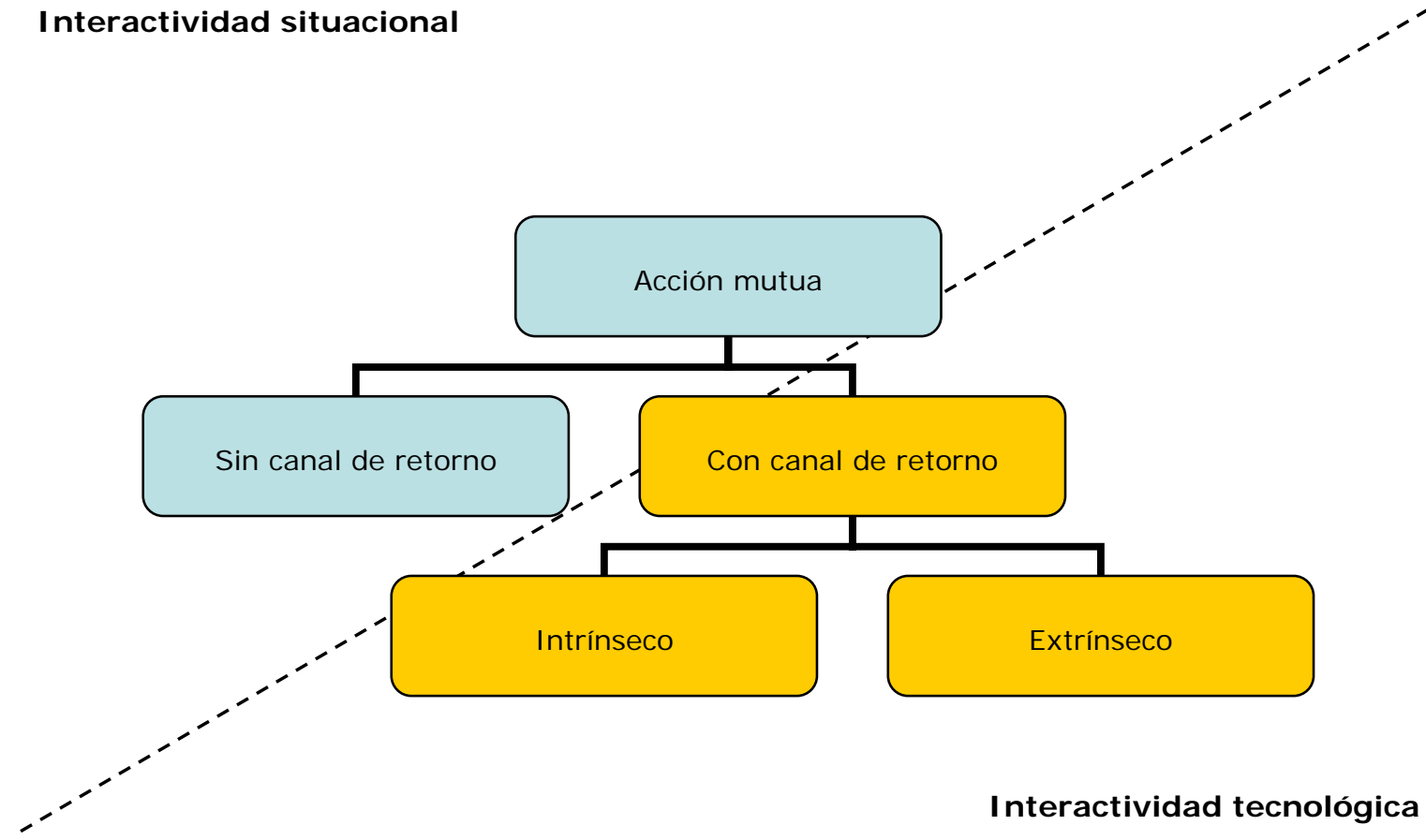

Fuente: elaboración propia a partir de Prado et al., 2006

Gráfico I. Tipos de interactividad

\begin{tabular}{|c|c|c|c|c|}
\hline PRODUCTO & AÑO & PLATAFORMA & I NCENTIVO & RESULTADOS \\
\hline Renault Clio & 1998 & Canal Satélite Digital & $\begin{array}{l}\text { Prueba del } \\
\text { producto }\end{array}$ & $\begin{array}{l}\text { 4.784 peticiones de prueba en } 4 \text { días } \\
8.387 \text { peticiones más en la segunda oleada } \\
\text { (diciembre 1999) }\end{array}$ \\
\hline Chrysler Neon & 1999 & Vía Digital & $\begin{array}{l}\text { uego prueba } \\
\text { vehículo }\end{array}$ & $\begin{array}{l}224.882 \text { posibles espectadores } \\
56.205 \text { accesos a la aplicación } \\
21.658 \text { ganadores del juego } \\
3.230 \text { solicitudes de catálogo } \\
2.182 \text { solicitudes de test-drive }\end{array}$ \\
\hline Nescafé de Nestlé & 1999 & Vía Digital & CD música & $\begin{array}{l}224.882 \text { posibles espectadores } \\
66.671 \text { accesos a la aplicación } \\
14.830 \text { ganadores de premio }\end{array}$ \\
\hline Renault Carminat & 2000 & $\begin{array}{l}\text { Canal Satélite Digital } \\
\text { Vía Digital }\end{array}$ & $\begin{array}{l}\text { Cine estreno } \\
\text { Palco gratuito }\end{array}$ & $\begin{array}{l}14.386 \text { contactos } \\
6.875 \text { ganadores }\end{array}$ \\
\hline Renault Scénic & 2000 & Canal Satélite Digital & Libro de viajes & 4.355 ganadores \\
\hline
\end{tabular}

Cuadro I. Primeras experiencias de publicidad interactiva en televisión en España 